\title{
INCIDÊNCIA DE DOENÇAS DIARREICAS NA BACIA DO RIO DOCE E AS RELAÇÕES COM INFRAESTRUTURA DE SANEAMENTO E O ROMPIMENTO DA BARRAGEM DE FUNDÃO - MARIANA/MG
}

\section{INCIDENCE OF DIARRHEAL DISEASES IN THE DOCE RIVER WATERSHED AND THEIR RELATIONSHIPTO SANITATION INFRASTRUCTURE AND THE FUNDÃO TAILINGS DAM FAILURE - MARIANA/MG}

\author{
Thiago Juarez Ferreira de Araújo \\ Graduação em Ciências Humanas e Geografia \\ Universidade Federal dos Vales do Jequitinhonha e Mucuri - UFVJM \\ Mestre em Análise e Modelagem de Sistemas Ambientais \\ Universidade Federal de Minas Gerais - UFMG \\ tgodmx@hotmail.com \\ Frederico Azevedo Lopes \\ Instituto de Geociências-Universidade Federal de Minas Gerais - UFMG \\ fredericolopes@ufmg.com \\ Camila Palhares Teixeira \\ Doutora em Ecologia pela Universidade Federal de Minas Gerais - UFMG \\ Professora do Centro Universitário de Sete Lagoas - UNIFEMM \\ camila.teixeira@unifemm.edu.br
}

\begin{abstract}
RESUMO
O rompimento da barragem de Fundão, localizada no município de Mariana-MG, ocorrido em novembro de 2015, trouxe graves consequências socioambientais, dentre elas, a interrupção da captação de água em diversas localidades. Considerando o risco associado à saúde humana, este trabalho busca analisar a distribuição espacial de doenças diarreicas em crianças de zero a quatro anos de idade nos municípios pertencentes à bacia do rio Doce e suas possíveis correlações com os serviços de abastecimento de água e esgotamento sanitário, bem como averiguar a possível influência do rompimento da barragem de Fundão sobre as taxas de incidência de doenças diarreicas nos municípios dependentes de captação de água do rio Doce. Apesar de não terem sido verificadas correlações significativas referentes à sazonalidade (Kruskal-Wallis), serviços de água e esgotamento sanitário (Spearman) e o rompimento da barragem sobre as taxas de incidência (Mann-Whitney), foi possível observar que a população infantil, é a mais vulnerável e a distribuição de casos estão, no decorrer dos anos, concentrados na porção norte e leste da bacia, por meio da autocorrelação espacial (Kernel e I de Moran). Deste modo, ressalta-se a necessidade de adoção de medidas eficazes de prevenção e controle da diarreia infantil nos municípios da bacia do rio Doce.
\end{abstract}

Palavras-Chave: Diarreia infantil. Saneamento. Autocorrelação espacial. Bacia do rio Doce.

\begin{abstract}
The rupture of the Fundão dam, located in the municipality of Mariana-MG, occurred in November 2015, brought serious socio-environmental consequences, among them, the interruption of water abstraction in several localities. Considering the risk associated with human health, this study aims to analyze the spatial distribution of diarrheal diseases in children from zero to four years of age in the municipalities belonging to the
\end{abstract}

Recebido em: 11/06/2019

Aceito para publicação em: 18/08/2019 
Doce river watershed and their possible correlations with water supply and sewage services, as well as to investigate the possible influence of the rupture of the Fundão dam on the incidence rates of diarrheal diseases in the municipalities dependent on water capitation of the Doce river. Although there were no significant correlation between seasonality (Kruskal-Wallis), water and sewage services (Spearman) and the dam rupture on the incidence rates (Mann-Whitney), it was possible to observe that the infant population is the most vulnerable and the case distribution is concentrated over the years in the northern and eastern portions of the basin through spatial autocorrelation (Kernel and I de Moran).Therefore, it is necessary to adopt effective measures for the prevention and control of infantile diarrhea in the municipalities of the Doce river basin.

Keywords: Childhood diarrhea. Sanitation. Spatial autocorrelation. River Doce watershed.

\section{INTRODUÇÃO}

O consumo de água contaminada é responsável por acarretar diversas doenças de veiculação hídrica, tais como a diarreia em menores de 5 anos de idade (ANDREAZZI et al., 2007) consistindo em um dos principais problemas de saúde pública no mundo, especialmente em países em desenvolvimento, onde os investimentos em infraestrutura sanitária são defasados e desiguais em relação aos países desenvolvidos (UNICEF, 2014; TEIXEIRA e PUNGIRUM, 2005).

A transmissão de doenças diarreicas pode ter relação com diversos fatores, dentre eles, a localização geográfica, as estações do ano referentes ao período seco e chuvoso, características das residências, qualidade da água e dos alimentos consumidos, condições socioeconômicas e ausência de saneamento adequado (PORTELA et al., 2011).

Neste contexto, a atual legislação que rege a respeito do saneamento básico no Brasil, foi criada em 05/01/2007 por meio da Lei no 11.445 (BRASIL, 2007) e regulamentada pelo Decreto $\mathrm{n}^{\circ}$ 7.217, de 21/06/2010 (BRASIL, 2010), atribuiu aos municípios, a responsabilidade pelo planejamento dos serviços de saneamento. Entretanto, diversas cidades brasileiras ainda se encontram despreparadas e desequipadas, sendo fundamental e oportuno constantes questionamentos a respeito dos rumos atuais do planejamento em saneamento, bem como seus objetivos e princípios em que são estruturados (SILVEIRA, 2012).

Além da carência de uma infraestrutura adequada, diversos municípios possuem seus principais mananciais sob influência de atividades potencialmente poluidoras, tais como a mineração (SOUSA e QUEMELO, 2015; AMORIN et al., 2016). Assim, o desastre ocorrido no dia 5 de novembro de 2015 chamou a atenção das mídias, de comunidades e órgãos ambientais do mundo todo. O rompimento da barragem de Fundão, pertencente à empresa Samarco Mineração S. A., no município de Mariana-MG, trouxe consequências socioambientais graves e bastante onerosas em escala regional, devido às suas proporções. Em situações como essa, há ainda o risco da população, motivada tanto pela escassez quanto pela insegurança em relação à qualidade das águas no sistema, buscar fontes alternativas de captação, que podem estar inconformes aos padrões sanitários (QUEIROZ et al., 2012).

Dessa forma, o presente estudo tem como objetivo principal analisar a distribuição espacial de doenças diarreicas, entre 2010 a 2017, em crianças de zero a quatro anos de idade nos municípios pertencentes à bacia do rio Doce e verificar as possíveis relações com abastecimento de água e esgotamento sanitário. Além disso, verificar a incidência de doenças diarreicas por faixa etária, sazonalidade e distribuição espacial, e averiguar a possível influência do rompimento da barragem de Fundão sobre as taxas de incidência de doenças diarreicas nos municípios dependentes de capitação de água do rio Doce.

\section{MATERIAIS E MÉTODOS}

A bacia do rio Doce está localizada na região Sudeste brasileira (Figura 1) e a área de drenagem é de aproximadamente 86 mil km², dos quais $86 \%$ pertencem ao Estado de Minas Gerais e o 
restante ao Espírito Santo. O rio Doce recebe esse nome a partir da confluência dos rios Piranga e Carmo, entre os municípios de Ponte Nova e Rio Doce em Minas Gerais. As nascentes do rio Doce estão todas situadas no Estado de Minas Gerais, nas serras da Mantiqueira e do Espinhaço, nas quais suas águas percorrem $850 \mathrm{~km}$, até atingir o oceano Atlântico no Espírito Santo (ANA, 2013).

Figura 01: Localização da bacia do rio Doce

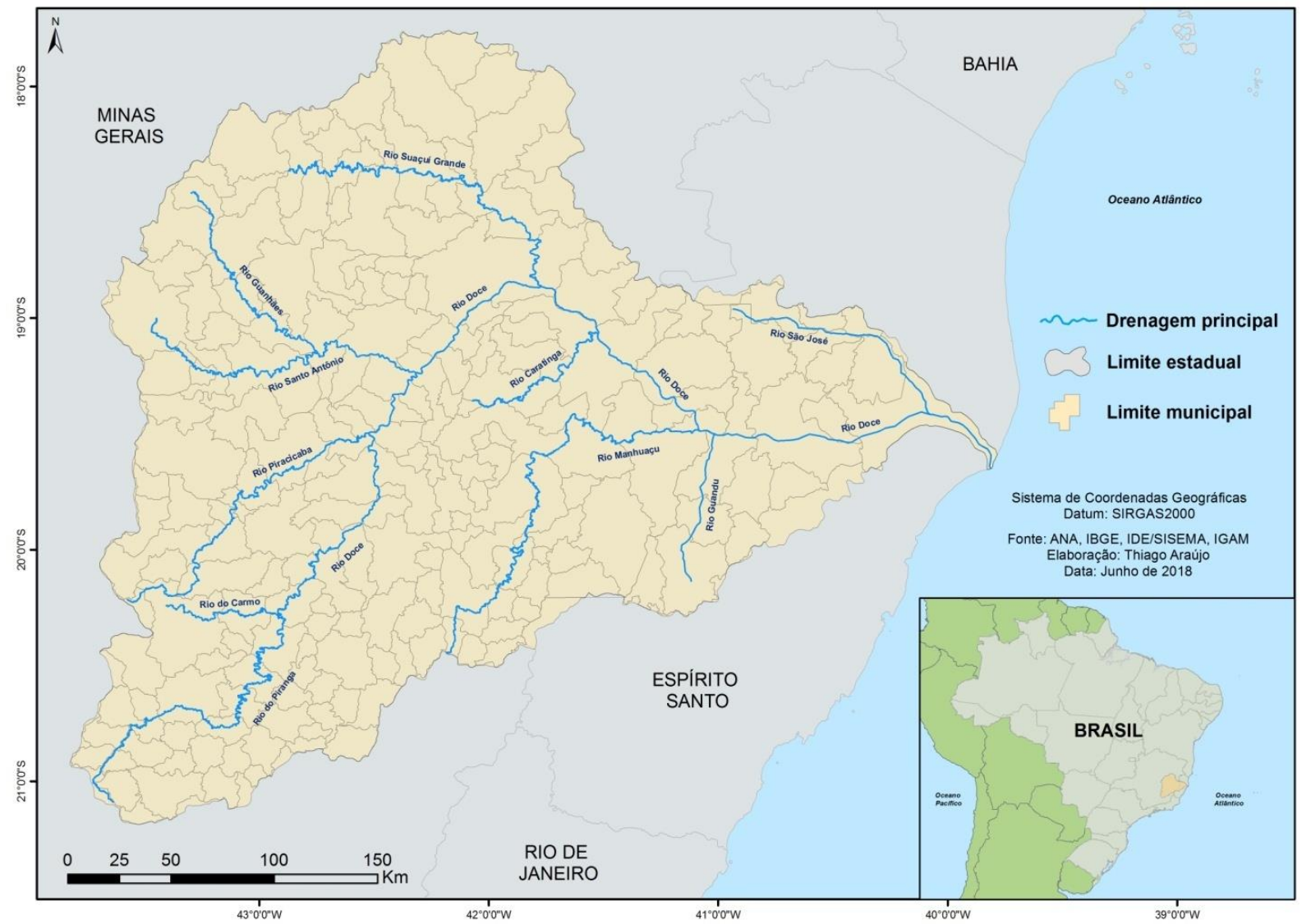

A sazonalidade da bacia do rio Doce é caracterizada por um período seco, entre abril e setembro, com precipitações que variam entre 150 a $250 \mathrm{~mm}$. Enquanto o período chuvoso vai de outubro a março, com precipitações que variam de 800 a 1300 mm (ANA, 2013, 2016).

Em 2019, estima-se que a população da bacia do rio Doce será superior a 3,6 milhões de habitantes, onde se destaca o Vale do Aço no Estado de Minas Gerais com maior adensamento populacional. Nota-se ainda, a existência de um fluxo migratório que se direciona, sobretudo, para as maiores cidades, como Ipatinga e Governador Valadares. Em decorrência, há uma tendência de diminuição populacional nos municípios com população de até 20.000 habitantes, que representam mais de $85 \%$ dos municípios da bacia do rio Doce (ANA, 2013) (Figura 2).

A população urbana representa mais de $70 \%$ da população total. Entretanto, os mesmos dados mostram que mais de 100 municípios (45\%), possuem população rural maior que a urbana, evidenciando que a população rural ainda é significativa, absorvidos pela exploração agropecuária. No Médio Doce, essas atividades constituem o principal gerador de renda, emprego e ocupação de mão de obra em municípios de menor porte, principalmente onde a população rural predomina (ANA, 2013). 
Figura 02: Distribuição populacional absoluta dos municípios da bacia do rio Doce

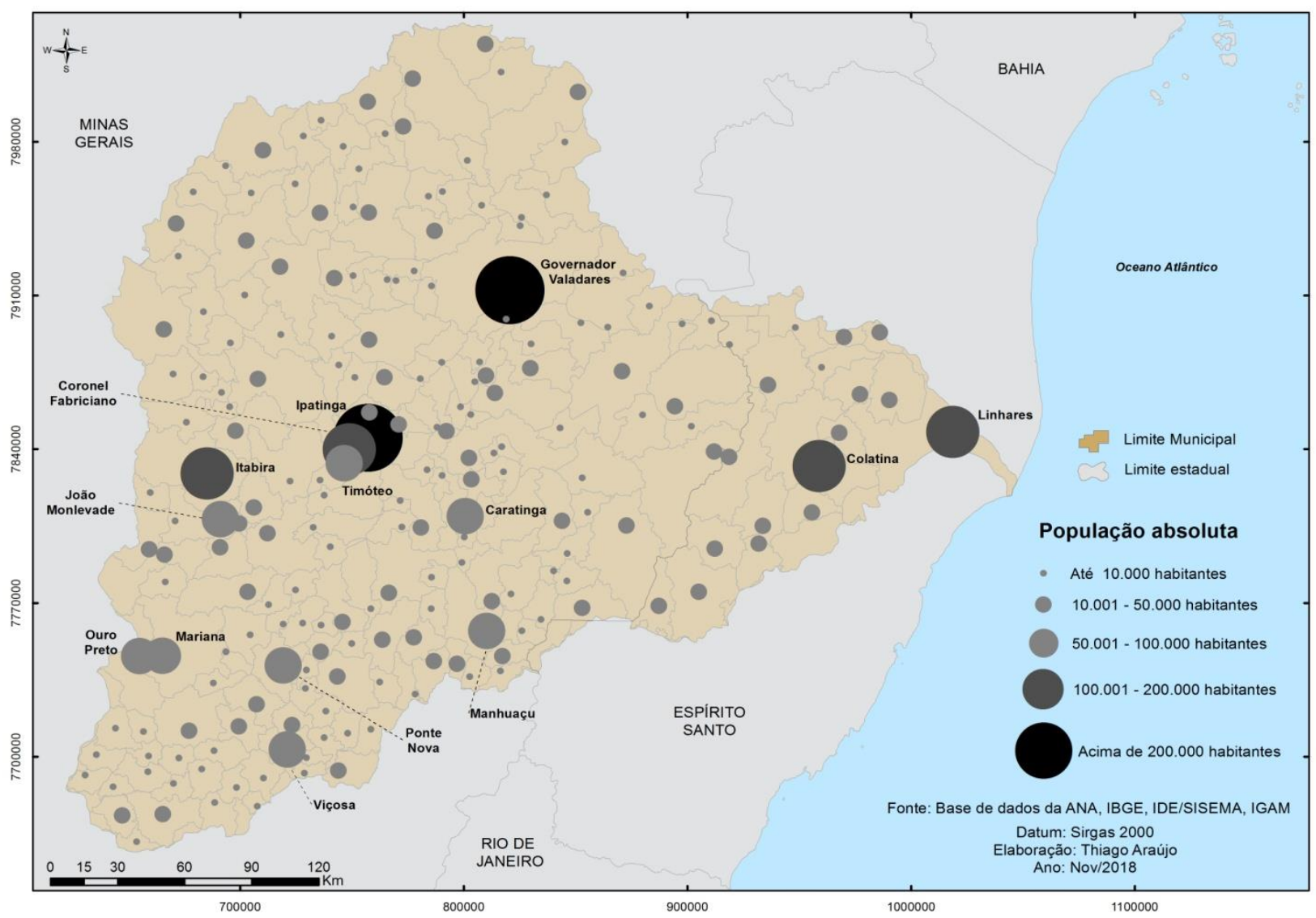

\section{PROCEDIMENTOS METODOLÓGICOS}

Esse estudo foi realizado em 225 municípios pertencentes à bacia do rio Doce localizada nos estados de Minas Gerais e Espírito Santo e, a população referência consiste em crianças de zero a quatro anos de idade. A coleta dos dados foi realizada junto ao Departamento de Informática do Sistema Único de Saúde (DATASUS), que teve como série histórica o período de janeiro de 2010 a dezembro de 2017, de doenças diarreicas e gastroenterite de origem infecciosa presumível notificadas pelo município (DATASUS, 2018). Além da coleta de dados da população referência desse estudo, foi coletado também os dados de todas as faixas etárias, sendo que foram formados três grupos etários ( 0 a 4 anos, 5 a 9 anos e acima de 10 anos) para fins de comparação entre as diferentes faixas etárias.

Para a análise das incidências de doenças diarreicas por grupos etários, foi realizado um Kruskal-Wallis, por meio do software $R$ ( $R$ Core Team, 2018), pois os dados não apresentam distribuição normal. Com base nos dados obtidos por internações de doenças diarreicas em crianças de zero a quatro anos de idade foi aplicado o estimador de densidade de kernel por meio do software ArcMAP do pacote ArcGIS 10.1. A análise exploratória de autocorrelação espacial foi realizada por meio da utilização dos índices de Moran Global (I) e Local (LISA), junto ao referido software.

Os shapefiles utilizados para a elaboração dos cartogramas presentes nesse estudo foram obtidos nas bases cartográficas da Agência Nacional de Águas (ANA, 2017), do Instituto Brasileiro de Geografia e Estatística (IBGE, 2016), da Infraestrutura de Dados Espaciais do Sistema Estadual do Meio Ambiente e Recursos Hídricos (IDE-SISEMA, 2017) e no Instituto Mineiro de Gestão das Água (IGAM, 2017).

Para a representação da distribuição sazonal das doenças diarreicas, considerou as taxas de internações mensais por diarreia e período chuvoso de outubro a março e o período seco de abril 
a setembro (BUSATO et al., 2013; ROCHA, 2012), de forma a ilustrar variações temporais nas taxas de incidência. Essa possível influência sazonal foi avaliada por meio do teste de MannWhitney no software R (R Core Team, 2018), pois os dados não apresentam distribuição normal.

Os dados relativos à infraestrutura de saneamento (abastecimento de água e tratamento de esgoto) foram obtidos junto ao Sistema Nacional de Informações sobre Saneamento (SNIS), por meio do uso de indicadores calculados a partir de dados fornecidos pelos prestadores de serviços de saneamento nos respectivos municípios (Quadro 1).

Quadro 01: Indicadores dos serviços de abastecimento de água e esgotamento sanitário adotados

\begin{tabular}{|c|c|}
\hline Código & Indicador \\
\hline $\begin{array}{l}\text { IN023- } \\
\text { AE }\end{array}$ & Índice de atendimento urbano de água \\
\hline $\begin{array}{l}\text { INO24- } \\
\text { AE }\end{array}$ & $\begin{array}{l}\text { Índice de atendimento urbano de esgoto referido aos municípios atendidos com } \\
\text { água }\end{array}$ \\
\hline $\begin{array}{l}\text { INO46- } \\
\mathrm{AE}\end{array}$ & Índice de esgoto tratado referido à água consumida \\
\hline $\begin{array}{l}\text { IN055- } \\
\text { AE }\end{array}$ & Índice de atendimento total de água \\
\hline $\begin{array}{l}\text { IN056- } \\
\text { AE }\end{array}$ & Índice de atendimento total de esgoto referido aos municípios atendidos com água \\
\hline
\end{tabular}

Fonte: Adaptado de SNIS (2017).

Assim, foi realizado um teste de correlação de Spearman, através do software $R$ ( $R$ Core Team, 2018) para relacionar as variáveis do SNIS citadas anteriormente com a incidência de doenças diarreicas na população da bacia do rio Doce.

Para a análise da possível influência do rompimento da barragem de Fundão sobre as taxas de incidência de doenças diarreicas dos municípios dependentes de captação de água do rio Doce, foi aplicado o teste de Mann-Whitney, por meio do software $R(R, 2018)$, pois os dados não apresentam distribuição normal. Deste modo, foi realizada a análise entre o período de dois anos anteriores ao rompimento (novembro de 2013) e dois anos após o evento (novembro de 2017).

A delimitação da área de influência foi realizada a partir de informações obtidas através da Força Tarefa logo após o rompimento da barragem em Mariana/MG (ANA, 2016). Dessa forma, 12 municípios foram selecionados, dos quais: Alpercata (MG), Governador Valadares (MG), Tumiritinga (MG), Galiléia (MG), Resplendor (MG), Itueta (MG), Baixo Guandu (ES) e Colatina (ES) apresentam dependência total. Os municípios de Aimorés (MG), Belo Oriente (MG), Periquito (MG) e Linhares (ES) dependem parcialmente da captação junto ao rio Doce.

A Figura 3 apresenta a estrutura geral dos materiais e métodos utilizados nessa pesquisa. 
Figura 3: Fluxograma dos Procedimentos Metodológicos

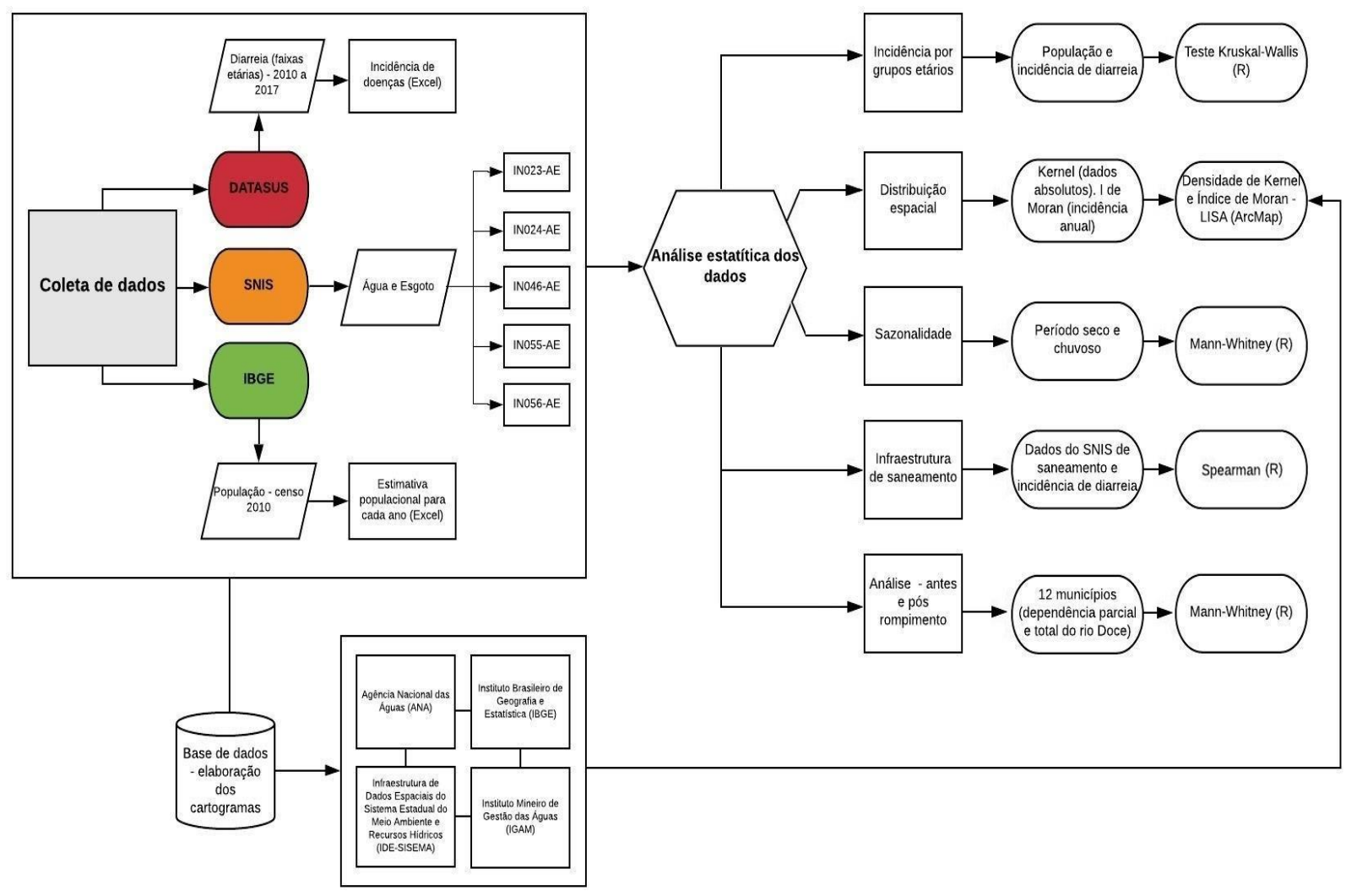

\section{RESULTADOS E DISCUSSÃO}

\section{Ocorrências de doenças diarreicas por faixa etária na bacia do rio Doce}

O resultado do teste Kruskal-Wallis, apresentado em boxplot na Figura 4, quando compara-se os casos de incidência da doença analisada e as diferentes faixas etárias estudados tem-se uma diferença estatisticamente significativa entre elas (Kruskal-Wallis chi-square $=20.569, p<0.001$ ), sendo que a faixa etária de 0 a 4 anos apresenta uma incidência maior às outras duas categorias e que existe diferença significativa também entre as categorias de 5 a 9 anos e acima de 10 anos.

As ocorrências de doenças diarreicas nos municípios da bacia do rio Doce totalizaram, em todas as faixas etárias, 35.284 casos entre janeiro de 2010 a dezembro de 2017. Na população de zero a quatro anos foram registrados 13.030 casos entre 2010 a 2017, sendo 9.159 verificados nos municípios localizados no estado de Minas Gerais e 3.871 no Espírito Santo, com incidência média anual de 6,4 casos para uma população de 1000 crianças. Entre as faixas etárias de cinco e nove anos o número de casos foi de 4.664, totalizando uma incidência de 2 casos, enquanto a partir de dez anos, o número de internações foi de 17.590, representando 0,7 ocorrências para cada 1000 habitantes.

Dessa forma, considera-se que as doenças diarreicas são propícias a ocorrerem em todas as faixas etárias, no entanto, a população infantil, especialmente menores de cinco anos de idade é considerada mais vulnerável, sendo uma das principais causas de morbidade e mortalidade (FEWTRELL et al., 2005; ANDREAZZI et al., 2007; PEREIRA e CABRAL, 2008; SABINO, 2016). Os fatores climáticos, sociais e ambientais como a origem e uso da água, destino dos dejetos, tratamento de efluentes, condições de moradia, origem e consumo de alimentos são alguns condicionantes responsáveis para maiores taxa de ocorrência de doenças diarreicas na população infantil (BARRETO et al., 2007; PORTELA et al., 2011; BUSATO et al., 2013). 
Figura 04: Boxplot da incidência de doenças diarreicas nas diferentes faixas etárias analisadas

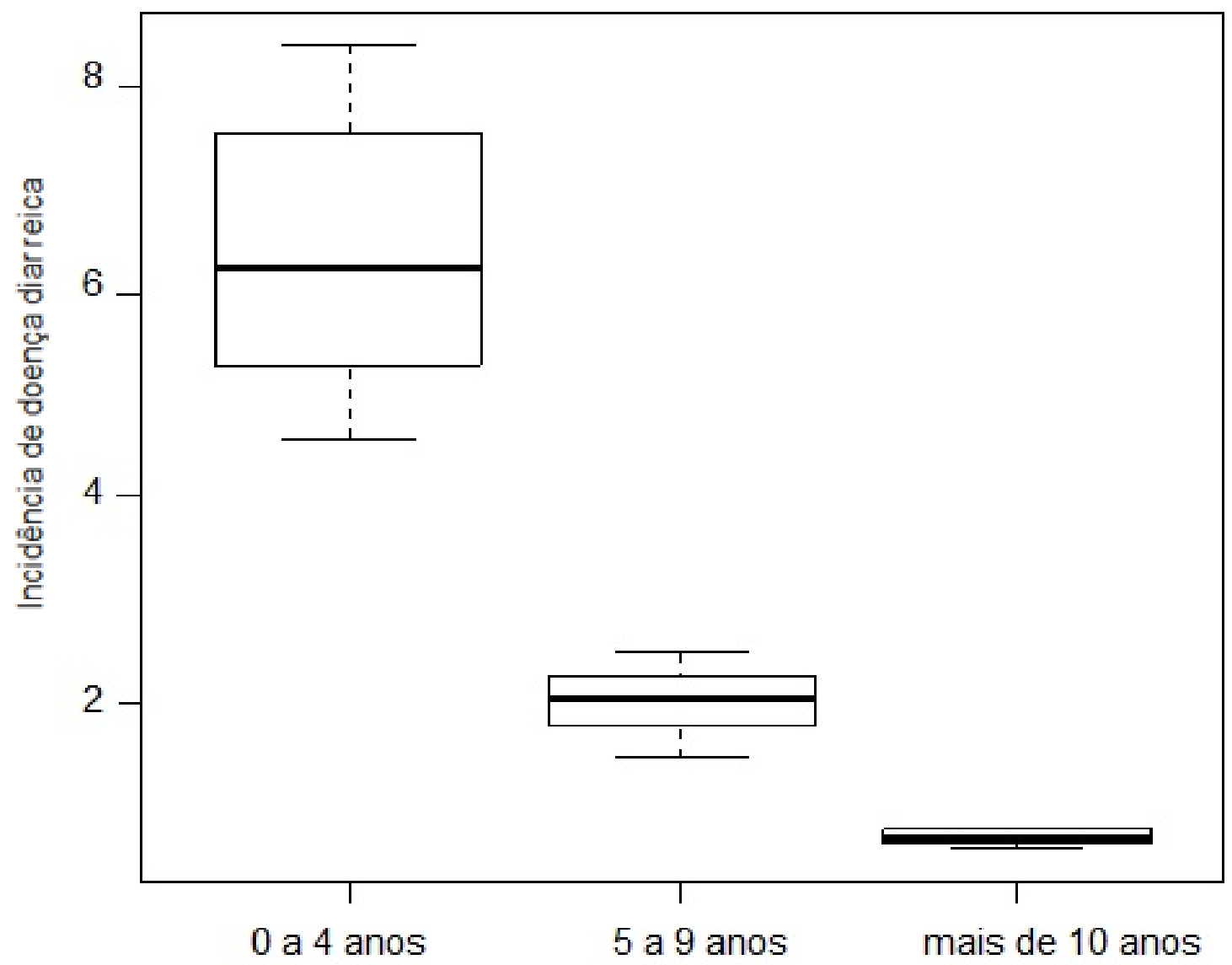

Um dos fatores importantes para o surgimento, bem como o controle de doenças diarreicas na população infantil está associado à escolaridade materna (CAMPOS et al., 1995; PORTELA et al., 2011). Dessa forma, alguns autores destacam a importância da criação de métodos e incentivos que amenizem as ocorrências de diarreia, como a educação sanitária (SABINO, 2016) e a lavagem de mãos (ESREY et al. 1985; CAIRNCROSS, 2003), sendo que esta medida pode ocasionar maiores impactos sobre as doenças diarreicas do que o próprio abastecimento de água e saneamento.

Contudo, é importante ressaltar, que os dados gerados em pesquisas referentes às doenças diarreicas ainda podem ser menores do que a realidade, tendo em vista que essas doenças não são de caráter de notificação compulsória, onde se pressupõe que somente em casos mais graves, busca-se assistência médica junto aos centros de saúde, dessa forma, ocorrendo muitas vezes deficiência no registro dos dados reais (BUSATO et al., 2013; JOVENTINO et al., 2013; SABINO, 2016).

\section{Distribuição e autocorrelação espacial das doenças diarreicas em crianças de 0 a 4 anos na bacia do rio Doce}

Em relação ao total absoluto de ocorrências no decorrer dos oito anos de análise (Figura 5), o município de Colatina/ES teve o maior número de ocorrências, totalizando 973 casos, seguido por Governador Valadares/MG (677), Baixo Guandu/ES (568), Resplendor/MG (372), Mutum/MG (371), Água Boa/MG e Santa Maria do Suaçuí/MG (322), Peçanha/MG (315), Aimorés/MG (283), Ipatinga/MG (277), Linhares/ES (258), Afonso Cláudio/ES e Sabinópolis/MG (257) e Manhuaçu/MG (235).

Os municípios de São João Evangelista e Viçosa localizados no estado de Minas Gerais apresentaram, respectivamente, 169 e 168 ocorrências. Já os municípios de Divino, Abre Campo, Coronel Fabriciano, Piranga, Itueta e Matipó tiveram entre 101 a 150 casos. O percentual entre 51 a 
100 casos representando $7,5 \%$ dos municípios. A maioria dos municípios da bacia do rio Doce apresentaram entre 1 a 50 casos correspondendo a $74 \%$ dos municípios. Por fim, vale lembrar que 18 municípios não tiveram nenhuma ocorrência de diarreia durante o período analisado.

Figura 05: Densidade de Kernel para casos absolutos de doenças diarreicas em crianças de zero a quatro anos de idade, de 2010 a 2017

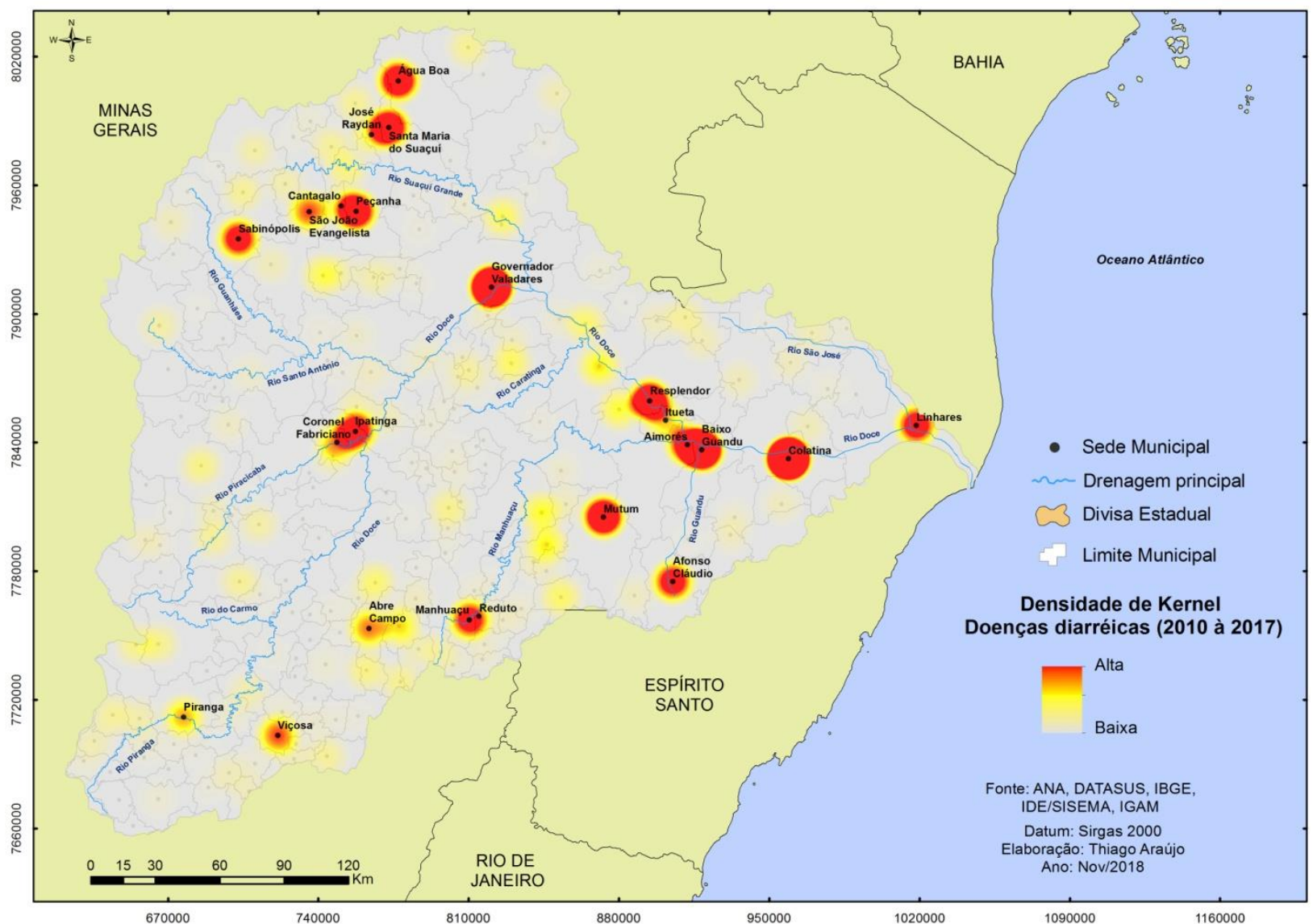

A aplicação do Índice de Moran (Local) para a produção de mapas (LISA) de autocorrelação espacial obteve-se como resultado, ao longo dos oito anos de análise, dois tipos de formação de clusters, sendo eles alta/alta e alta/baixa, sendo que o último ocorreu somente no ano de 2010 (Figuras 6 a 9). Os resultados que apresentam "alta/alta", significa que esses municípios e também os municípios vizinhos resultam em altas taxas de internação por diarreia. Já o "alta/baixa", revela que um município apresenta altas taxas de internações, no entanto, os municípios vizinhos tem baixas taxas do mesmo. O "não significativo" indica que esses municípios não apresentam resultados estatisticamente significantes, dessa forma indica aleatoriedade na correlação espacial.

Em geral, percebe-se que no decorrer dos oito anos de análise, a formação de clusters alta/alta estabeleceram espacialmente nas mesmas regiões com pequenas alterações. Na parte norte, localizados na sub-bacia do rio Suaçuí, e leste, na divisa dos estados de Minas Gerais e Espírito Santo, na área de encontro dos rios Manhuaçu e Guandu com o rio Doce, alternando apenas alguns municípios. Somente nos anos de 2013 (Figura 7), 2014 (Figura 8) e 2017 (Figura 9) que houve uma formação de clusters alta/alta na região sudoeste, localizados na sub-bacia do rio Piranga. 
Figura 06: Clusters de incidência de doenças diarreicas anuais em crianças de 0 a 4 anos, 2010 e 2011

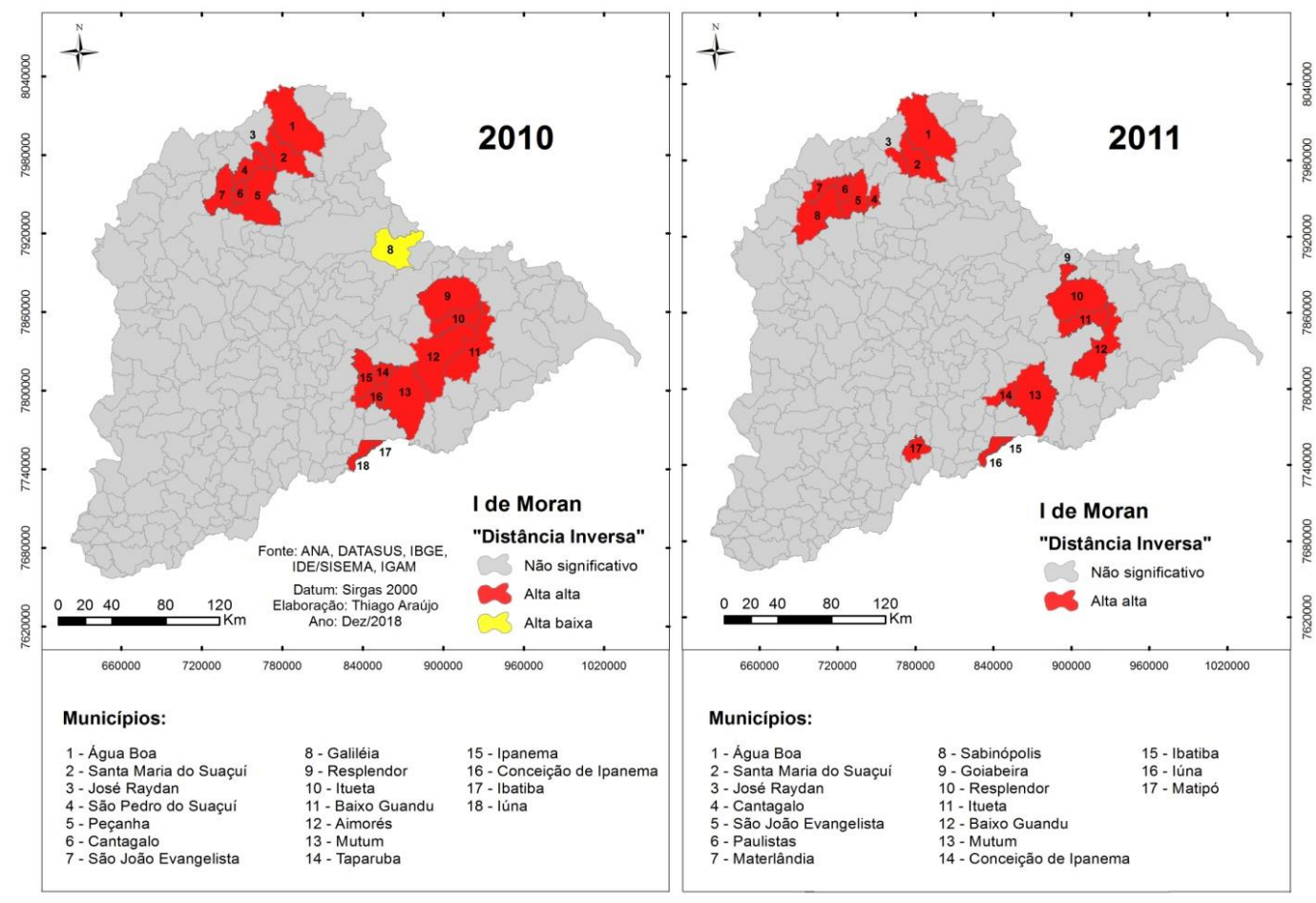

Figura 07: Clusters de incidência de doenças diarreicas anuais em crianças de 0 a 4 anos, 2012 e 2013

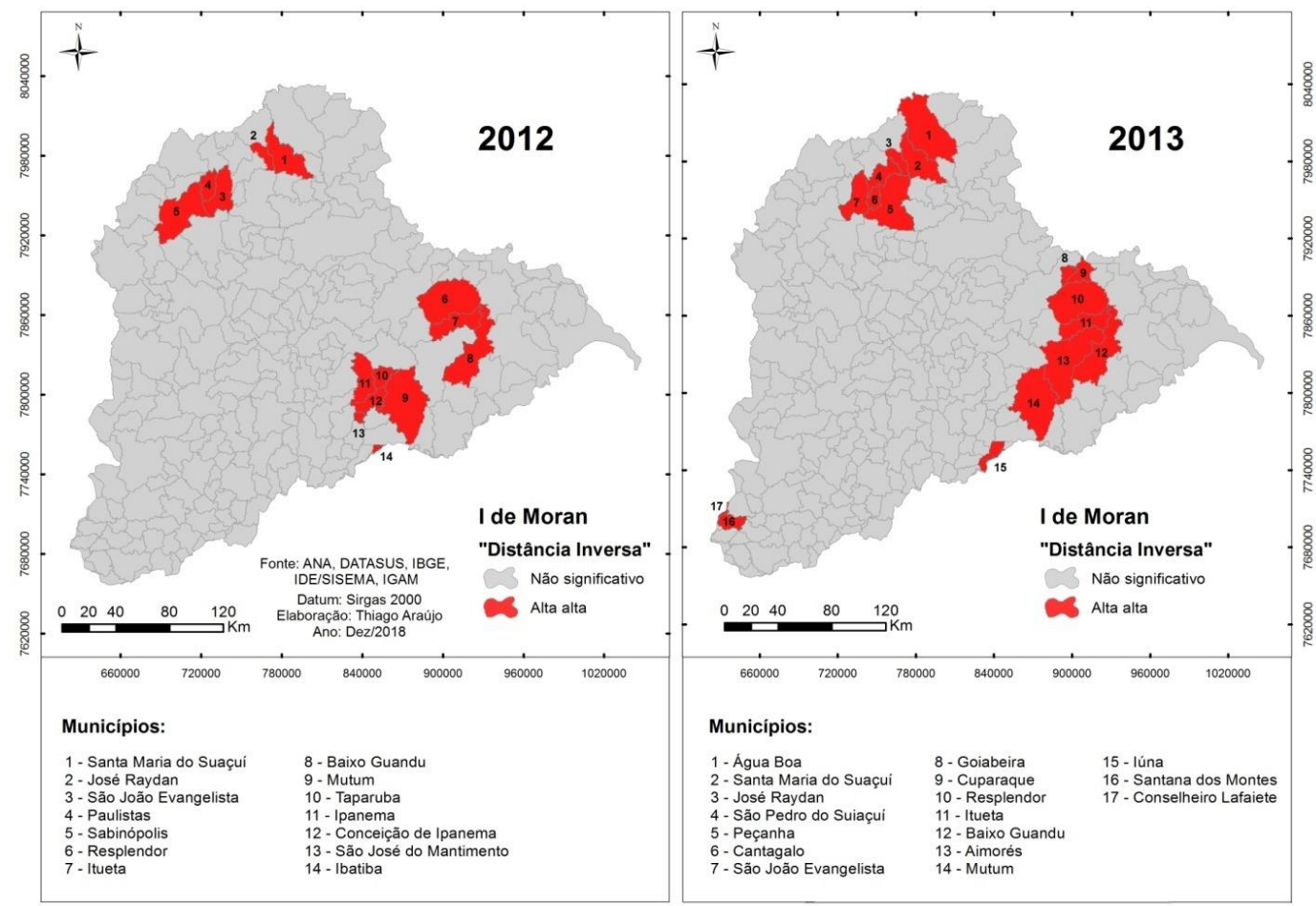


Figura 08: Clusters de incidência de doenças diarreicas anuais em crianças de 0 a 4 anos, 2014 e 2015

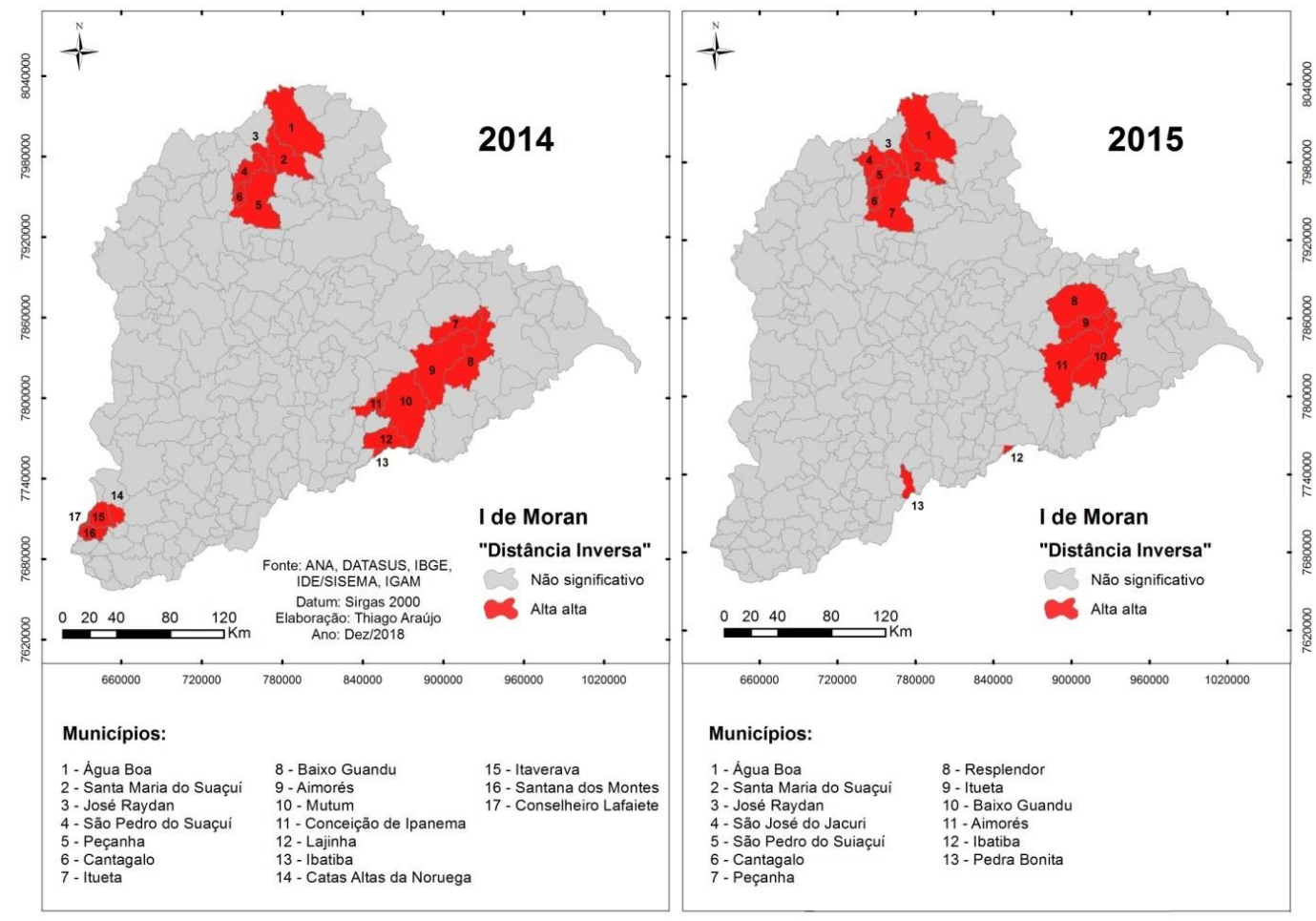

Figura 09: Clusters de incidência de doenças diarreicas anuais em crianças de 0 a 4 anos, 2016 e 2017
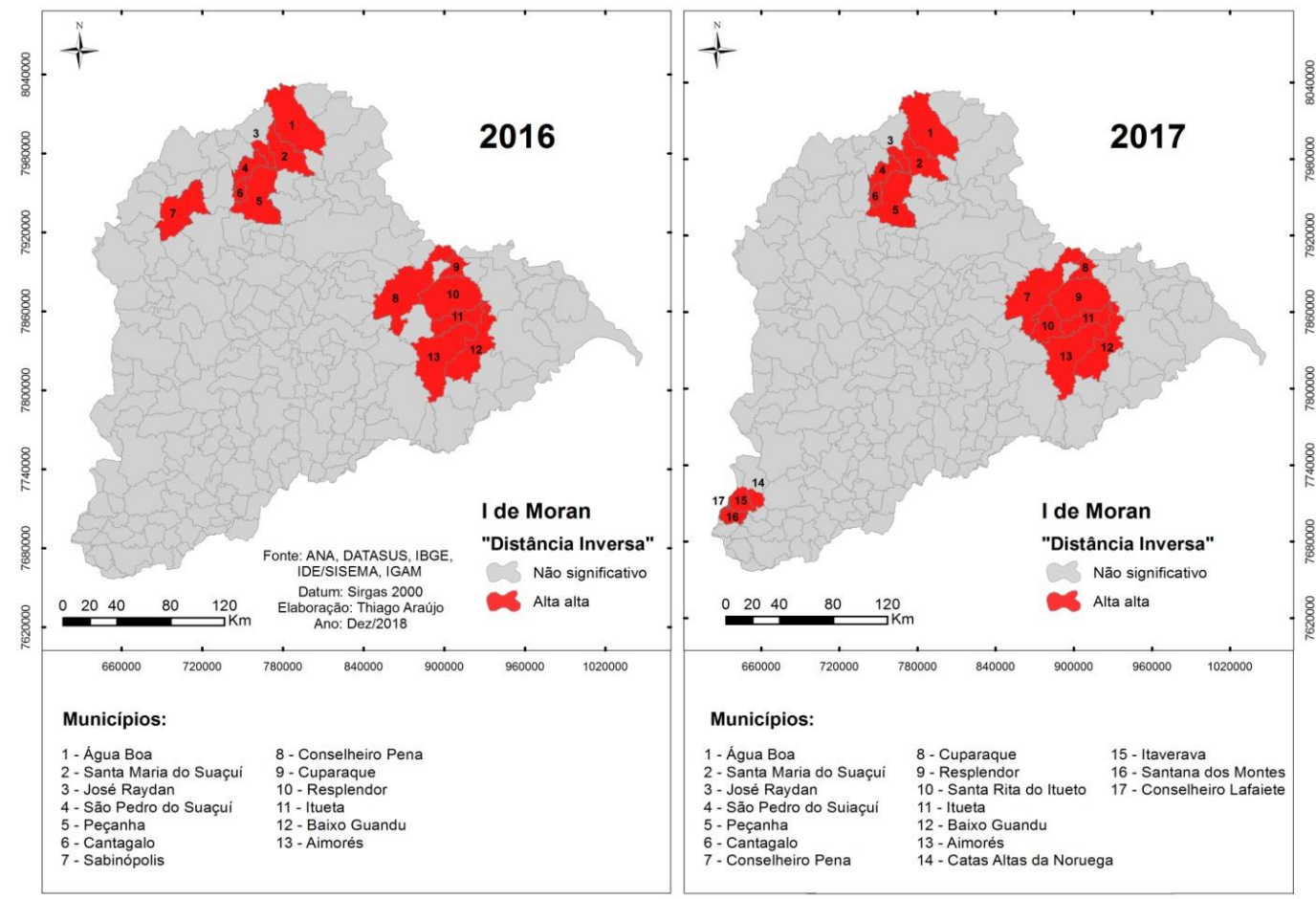
A respeito dos municípios que estão localizados na porção leste da bacia do rio Doce, as condições de abastecimento de água, bem como tratamento de esgoto, apresentaram condições inferiores ao restante dos municípios da bacia. Os dados oriundos do SNIS, referentes ao ano de 2016, mostram que nesses municípios, a média de atendimento total de água para a população foi de $54 \%$, enquanto a média de atendimento de esgotamento sanitário foi pouco mais de $65 \%$ da população.

O fornecimento de água própria para o consumo humano, assim como o saneamento adequado tem efeitos positivos na saúde da população, portanto, é fundamental não só para construir instalações para esses serviços, mas também garantir que eles funcionem corretamente. Além do mais, vale lembrar que programas de educação em saúde tem um efeito muito reduzido sobre práticas reais de higiene (BRISCOE, 1987).

Dentre os municípios localizados na região norte da bacia, em $70 \%$ deles a população rural é maior que a urbana, sendo esse, um condicionante que pode estar relacionado aos elevados índices de diarreia nessa região.Alguns estudos abordam a susceptibilidade em localidades rurais para elevados índices de diarreia (AMARAL et al., 2003; RAZZOLINI E GUNTHER, 2008; PORTELA et al., 2011). Em áreas rurais, as principais fontes de fornecimento de água para o uso doméstico são em poços rasos e nascentes, dessa forma, o risco de ocorrência de surtos de doenças de veiculação hídrica, como a diarreia, são elevados, onde a forma de captação da água, bem como seu uso, se torna um agravante para altos índices de doenças (AMARAL et al., 2003).

Além dos condicionantes supracitados anteriormente, a carência de atendimentos médicos, especialmente em virtude de dificuldades logísticas, a essas localidades, pode também está relacionado aos elevados índices de doenças diarreicas em áreas rurais (IMADA et al., 2016), no entanto, torna-se necessário estudos mais robustos que verifiquem esta hipótese.

\section{Infraestrutura de abastecimento de água, esgotamento sanitário e suas possíveis relações com doenças diarreicas na bacia do rio Doce}

De maneira geral, os índices de cobertura de abastecimento de água nos domicílios dos municípios pertencentes à bacia do rio Doce são satisfatórios (apresentar os dados), entretanto, no que diz respeito à cobertura dos sistema de esgotamento sanitário, algumas sub-bacias necessitam de maiores atenções, tanto em Minas Gerais (Caratinga, Santo Antônio, Suaçuí e Manhuaçu), quanto no Espírito Santo (Santa Maria do Doce) apresentam valores abaixo da média dos estados mineiro e capixaba (ANA, 2013).

No entanto, o teste estatístico de Correlação de Spearman utilizado nessa pesquisa, mostrou que a relação de abastecimento de água e esgotamento sanitário não são significativos para nenhuma das variáveis analisadas nesse trabalho, ou seja, a incidência de doenças diarreicas na bacia do rio Doce, não são explicados pela influência das referidas variáveis (Figura 10).

Apesar dos resultados não apresentarem significância estatística, é necessário analisar condições de saneamento nesses municípios, especialmente nos que carecem de assistência otimizada por parte dos órgãos competentes. A implementação de um conjunto de ações de educação orientadas para a aquisição de consciência política por parte da população é essencial para atuar em prol de sua saúde, bem como uma estrutura institucional eficiente atenta à relevância da participação popular e, especialmente, da inclusão social (SOUZA e FREITAS, 2008).

A respeito dos dados utilizados nessa pesquisa oriundos do SNIS, vale lembrar que a aquisição destes dados depende da solicitude dos funcionários em preencher os questionários enviados para coletar informações, no entanto é importante ressaltar a iniciativa do governo em subsidiar a obtenção de informações detalhadas relativas ao saneamento nos municípios brasileiros (RUBINGER, 2008; BRASIL, 2011).

A proposta feita por Rubinger (2008), implica em uma elaboração de diagnóstico anual da gestão dos serviços públicos de saneamento, abrangendo as informações de interesse sobre esses assuntos e que deverá ser alimentado pelas administrações dos municípios e pelo também pelo Governo Federal, na qualidade de titulares, e também pelas entidades reguladoras. A distinção na forma de abordar os serviços dificulta a interface entre dados que são complementares, permitindo assim uma melhor reflexão a respeito da realidade sanitária dos municípios brasileiros. 
Figura 10: Correlações entre as variáveis de saneamento e os índices de doenças diarreicas na população da bacia do rio Doce

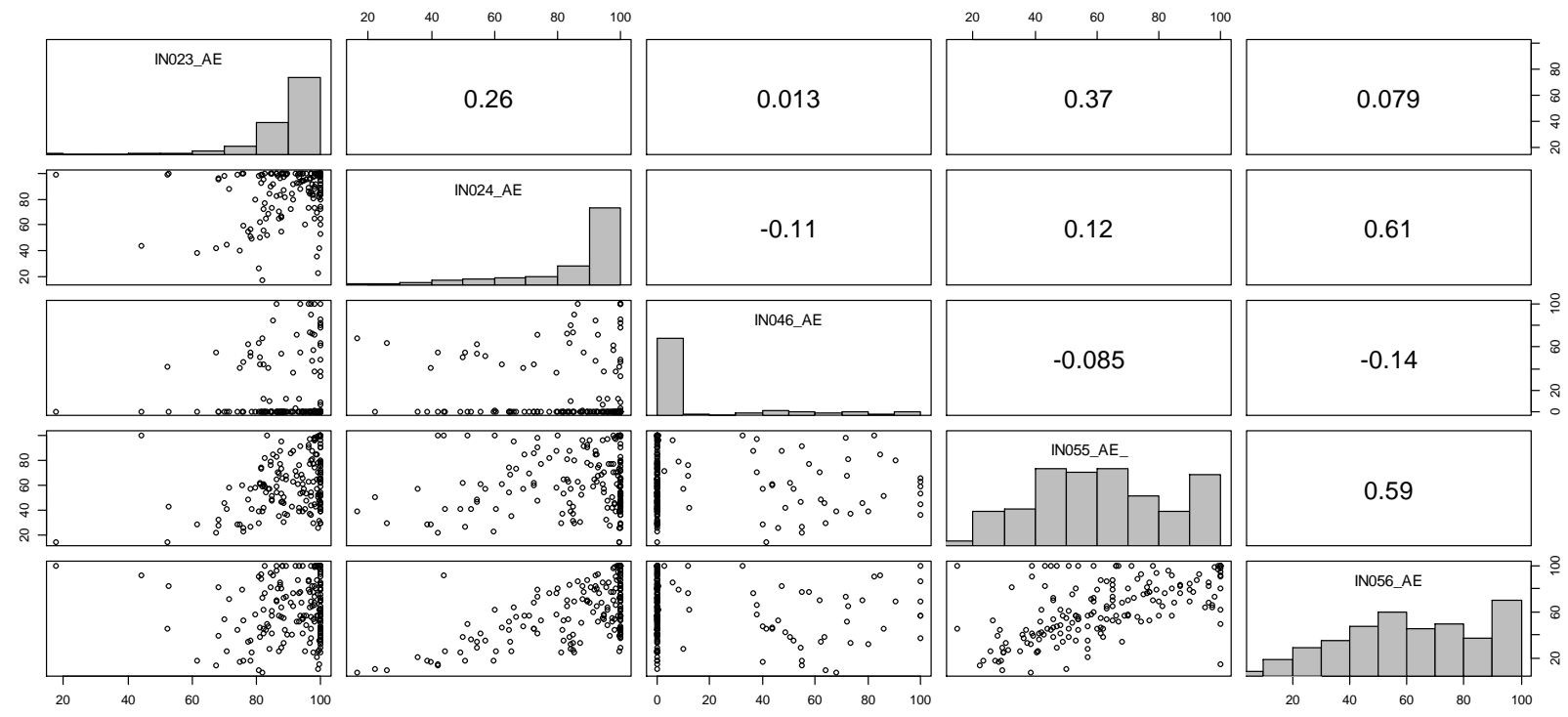

Outro fator pertinente a ser destacado consiste na vulnerabilidade para a obtenção das informações pretendidas, bem como de sua representatividade e também do real alcance da pesquisa. Tendo em vista que, os dados provenientes do SNIS são realizados em questionários autodeclarados, dessa forma o retorno muitas vezes pode ser inferior ao esperado (RUBINGER, 2008; BRASIL, 2011).

Influência sazonal sobre a incidência de doenças diarreicas em crianças de 0 a 4 anos na bacia do rio Doce

Apesar de os maiores índices de diarreia geralmente ocorrerem no período chuvoso (ANDREAZZI et al., 2007; ROCHA, 2012; BUSATO et al., 2013;), o efeito da sazonalidade sobre a incidência de doenças diarreicas em crianças de zero a quatro anos não foi significativa na bacia do Rio Doce no período analisado $(\mathrm{W}=1366, \mathrm{p}=0.1177)$ (Figura 11). Neste contexto, a possível interferência da subnotificação de casos nos resultados observados, consiste em um fator a ser considerado (RUBINGER, 2008; BRASIL, 2011).

Figura 11: Boxplot da incidência de doenças diarreicas por estação seca e chuvosa

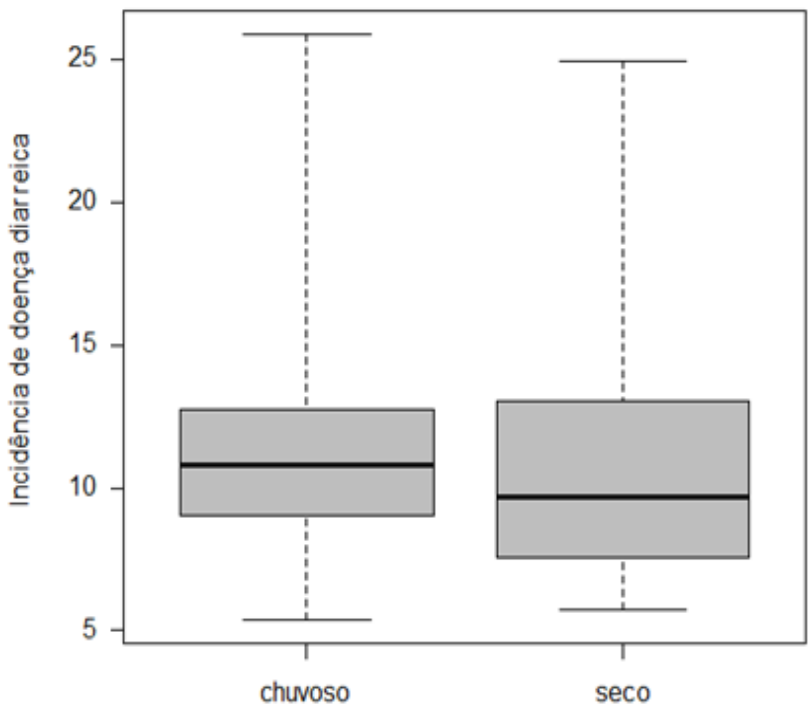




\section{Doenças diarreicas e as possíveis relações com o rompimento da barragem de Fundão}

Apesar da hipótese do aumento dos índices de doenças diarreicas após o rompimento da barragem de Fundão, devido ao possível consumo de água imprópria e de qualidade duvidosa, bem como a utilização de fontes alternativas sem o devido tratamento, os resultados da estatística descritiva não demonstraram tal situação (Figura 12). A redução observada no resultado da mediana no período anterior ao rompimento $(6,7)$ e posterior $(2,4)$ para os índices de doenças diarreicas nesses municípios que dependem de captação de água do rio Doce, seja parcialmente ou totalmente, poderia estar condicionado à insegurança da população em consumir diariamente as águas oriundas do rio Doce, o que pode levar ao aumento no consumo de água industrializada nesses municípios (p.ex. QUEIROZ et al., 2012). No entanto, necessita-se de estudos epidemiológicos que comprovem essa hipótese.

Figura 12: Boxplot da incidência de doenças diarreicas antes e depois do rompimento da barragem de Fundão

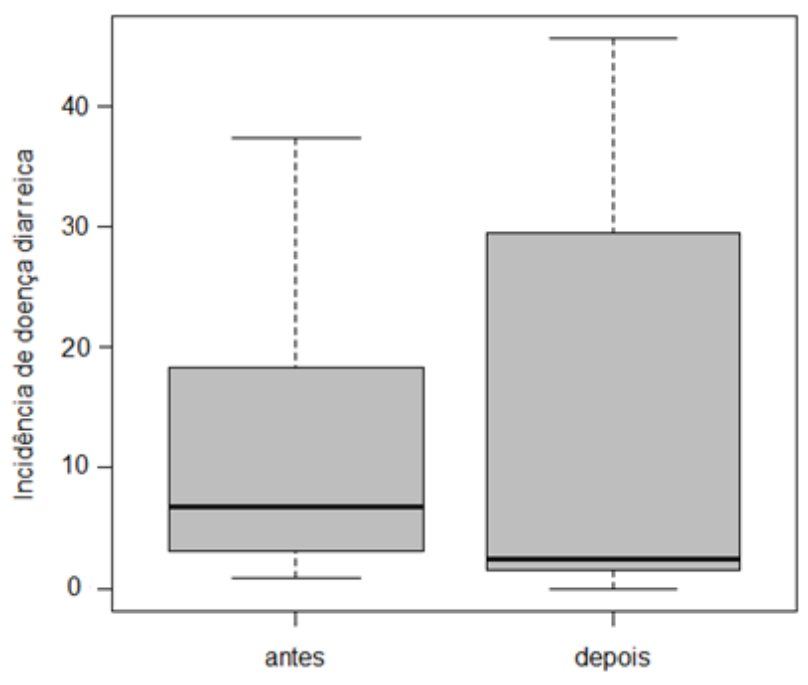

Entretanto, a incidência de doenças diarreicas em crianças de zero a quatro anos de idade, antes (novembro de 2013 até novembro de 2015) e pós (novembro de 2015 até novembro de 2017) rompimento da barragem de Fundão nos municípios que dependem de captação de água do rio Doce não foi estatisticamente significativa ( $W=81, p=0.6297)$.

Vale ressaltar que a vulnerabilidade da população e da área geográfica afetada é um dos fatores que intensificam ainda mais os efeitos causados pelo rompimento da barragem, tanto a magnitude do evento, como as consequências socioeconômicas, ambientais e sanitárias levam danos irreparáveis à saúde física e mental das populações atingidas (ROCHA et al., 2016).

Assim como em Governador Valadares, Colatina também se encontra com os mesmos problemas de captação de água do rio Doce. Ainda que a prefeitura municipal afirme que existem laudos que comprovam a qualidade da água para o consumo, o Ministério Público pediu a suspensão alegando a existência de materiais pesados acima dos padrões de segurança e potabilidade (G1.COM, 2015; UOL.COM, 2015). Em situações como essa, há ainda o risco de a população, motivada tanto pela escassez quanto pela insegurança em relação à qualidade das águas no sistema, buscar fontes alternativas de captação, que podem estar inconformes aos padrões sanitários.

Portanto, é importante destacar que nas áreas afetadas pelo rompimento da barragem, bem como em localidades carentes e excluídas de rede de serviços públicos, a falta de acesso a fontes seguras de água, se torna um fator agravante e nociva à saúde humana. Dessa forma, a busca da população por fontes alternativas de água, pode levar ao consumo de água com qualidade sanitária duvidosa e, em volume irregular e insuficiente para atender as necessidades básicas da população (RAZZOLINI E GUNTHER, 2008). 


\section{CONSIDERAÇÕES FINAIS}

Os resultados obtidos nesse estudo, permitiu levantar e discutir hipóteses a respeito da ocorrência de doenças diarreicas presentes nos municípios da bacia do rio Doce.

Em relação à incidência de diarreia por grupos etários constatados nos municípios pertencentes à bacia do rio Doce, percebe-se que as doenças diarreicas acometem a todas as faixas etárias, onde a população infantil, especialmente de 1 a 4 anos de idade, está mais propícia e vulnerada a essas enfermidades. Nota-se ainda, que a média nacional, mineira e capixaba de incidência de diarreia nesse período é menor que as taxas registradas nos municípios da bacia.

No que diz respeito à sazonalidade das doenças, esperava-se nessa pesquisa, que as maiores taxas de ocorrências de doenças diarreicas ocorreriam nos meses considerados chuvosos (outubro a março), e as menores taxas nos meses secos (abril a setembro). Entretanto, a sazonalidade não foi evidenciada nesse estudo.

Em relação à autocorrelação espacial, percebe-se que as altas taxas de doenças diarreicas na população infantil se concentraram nas porções norte e leste da bacia, entre 2010 a 2017. Tais resultados podem estar atribuídos tanto a ruralidade dos municípios na porção norte, quanto na integridade do abastecimento de água e tratamento efluentes sanitários na região leste da bacia do rio Doce.

Esta constatação aponta a importância contínua de estudos mais robustos nessa área, tendo em vista a importância da gestão de recursos hídricos, tanto em localidades urbanas quanto rurais, que possam garantir o suprimento de água em quantidade e qualidade para atender a todas as necessidades da população. Além disso, a não correlação da incidência de diarreia infantil com a qualidade de abastecimento de água e esgotamento sanitário abre caminhos para uma reflexão quanto à veracidade e metodologia na obtenção de dados.

Assim sendo, vale salientar que as principais limitações encontradas nessa pesquisa, referem-se, especialmente, a utilização de bancos de dados secundários, tanto do DATASUS quanto do SNIS, implicando em uma possível irregularidade na notificação de ocorrência de casos e à possível oscilação do número de unidades notificadoras. Além da ausência de dados em redes privadas de saúde não conveniadas, dessa forma, essas limitações podem resultar em subestimativa das incidências reais de doenças diarreicas presentes na bacia do rio Doce.

Apesar de não existir diferença significativa, tanto no aumento quanto na diminuição da média de incidência de diarreia no período de pós-rompimento da barragem de Fundão, essa pesquisa recomenda que o monitoramento e a avaliação das doenças diarreicas sejam feitos continuamente e que suas ações impliquem uma integração efetiva entre as diversas esferas da saúde, de forma a produzir resultados de curto, médio e de longo prazo que auxiliem órgãos competentes no planejamento de medidas mais eficazes de prevenção e controle da diarreia infantil na bacia do rio Doce.

Vale mencionar, que o caso de Mariana não serviu de exemplo para que novos desastres dessa natureza fossem evitados. Em um curto intervalo de tempo, ocorreu o rompimento da barragem da mina do Córrego do Feijão, localizada no município de Brumadinho em Minas Gerais, causando impactos ambientais e perdas humanas de grandes proporções. Além disso, a população que vive nas proximidades de barragens interditadas devido ao alto grau de instabilidade convivem com o medo e a vulnerabilidade diante do risco iminente de rompimento. Portanto, a qualidade duvidosa da água do rio Doce para o consumo, com consequências prejudiciais à saúde da população, agora se repete no rio Paraopeba, carecendo de constantes investigações e tomada de decisões por parte dos órgãos responsáveis para que outros eventos dessa magnitude não voltem a ocorrer devido à negligência humana.

\section{REFERÊNCIAS}

AMARAL, L. A.; FILHO, A., N.; ROSSI JUNIOR, O., D.; FERREIRA, F., L., A.; BARROS, L., S., S. Água de consumo humano como fator de risco à saúde em propriedades rurais.Revista de Saúde Pública. v. 34, n. 4, p. 510 - 4, 2003. https://doi.org/10.1590/S0034-89102003000400017 
AMORIM, N. A.; CONCEIÇÃO, T. L. A.; FERREIRA, P. A. Mineração de agregados e saúde pública: uma perspectiva socioambiental nas comunidades rurais Sagui 1 e 2. Educação, Tecnologia e Cultura - E.T.C., [S.I.], n. 14, 2016.

Disponível em: <https://publicacoes.ifba.edu.br/index.php/etc/article/view/44>. Acesso em: mar/2019.

ANA - Agência Nacional de Águas (Brasil). Plano integrado de recursos hídricos da bacia

hidrográfica do rio Doce: relatório executivo / Agência Nacional de Águas. -- Brasília: ANA, 2013, 129 p.

ANA - Agência Nacional de Águas. Encarte Especial sobre a Bacia do Rio Doce: Rompimento da barragem em Mariana/MG. Brasília: 2016. Disponível em:

<http://arquivos.ana.gov.br/RioDoce/EncarteRioDoce_22_03_2016v2.pdf>. Acesso em: 15 nov. 2017.

ANA - Agência Nacional de Águas. Bases Cartográficas Digitais. 2017. Disponível em: < http://dadosabertos.ana.gov.br/search>. Acesso em: maio de 2017.

ANDREAZZI, M. A. R.; BARCELLOS, C.; HACON, S. Velhos indicadores para novos problemas: a relação entre saneamento e saúde. Revista Panamericana de Salud Pública. Washington, 22(03), p. 211-217, 2007. Disponível em: <http://www.scielosp.org/pdf/rpsp/v22n3/a08v22n3.pdf>. Acesso em: julho de 2018. https://doi.org/10.1590/S1020-49892007000800008

BARRETO, M. L.; GENSER, B.; STRINA, A.; TEIXEIRA, M. G.; ASSIS, A. M. O.; REGO, R. F.; TELES, C. A.; PRADO, M. S.; MATOS, S. M. A.; SANTOS, D. N.; SANTOS, L. A.; CAIRNCROSS, S. Effect of city-wide sanitation programme on reduction in rate of childhood diarrhoea in northeast Brazil: assessment by two cohort studies. Lancet, v. 370, p. 1622-28, 2007. https://doi.org/10.1016/S0140-6736(07)61638-9

BRASIL. Lei no $\mathbf{1 1 . 4 4 5}$ de 05 de janeiro de 2007. Estabelece as diretrizes nacionais para o saneamento básico. Brasília: Diário Oficial da União, Seção 1, p. 3-7, 2007. Disponível em: <http://www.in.gov.br>. Acesso em: out de 2018.

BRASIL. Decreto № 7.217, de 21 de junho de 2010. Regulamentada a Lei no 11.445, de 5 de janeiro de 2007, que estabelece diretrizes nacionais para o saneamento básico, e dá outras providências. 2010. Disponível em: < http://www.planalto.gov.br/ccivil_03/_Ato2007-

2010/2010/Decreto/D7217.htm>. Acesso em: out de 2018.

BRASIL, Ministério das Cidades. Panorama do saneamento básico no Brasil: cadernos temáticos para o panorama do saneamento básico no Brasil. vol. VII. Brasília: Ministério das Cidades, 2011, $647 p$.

BRISCOE, J. Abastecimento de agua y servicios de saneamiento. Sufuncionenlarevolucion de lasupervivencia infantil. Bulletinofthe Pan American Health Organization, v. 21, n. 2, 1987.

BUSATO, M. A.; LUTINSKI, J. A.; SOUZA, M. F.; CECHIN, F.; GENNARI-FILHO, D.; PERIPOLLI, C.; MARANGONI, S. R.; CONSTANCIA, C. Distribuição de Doenças Diarreicas Agudas em Municípios do Estado de Santa Catarina.Hygeia- Revista Brasileira de Geografia Médica e da Saúde, v.9, n.16, p. 19-27, 2013.

CAIRNCROSS, S. Handwashing with soap - a new way to prevent ARIs?Tropical Medicine And International Health, v. 8, n. 8, p.1-3, 2003. https://doi.org/10.1046/j.1365-3156.2003.01096.x

CAMPOS, G. J. V.; REIS FILHO, S. A.; SILVA, A. A. M.; NOVOCHADLO, M. A. S.; SILVA, R. A.; GALVÃO, C. E. S. Morbimortalidade infantil por diarréia aguda em área metropolitana da região Nordeste do Brasil, 1986-1989.Rev de Saúde Pública, v. 29, n. 2, p. 132-139, 1995.

DATASUS - Informações de Saúde do Sistema Único de Saúde do Ministério da Saúde. Indicadores geral, por local de internação, a partir de 2008. Disponível em: <

http://www2.datasus.gov.br/DATASUS/index.php?area=0203\&id=6926\&VObj=http://tabnet.datasus.go v.br/cgi/deftohtm.exe?sih/cnv/ni >. Acesso em: maio de 2017.

ESREY, S. A. Interventions for the control of diarrhoeal disease among young children: improving water supplies and excreta disposal facilities. Bulletin of the World Health Organization, n. 63, p. 757-772, 1985.

FEWTRELL, L.; KOUFMANN, R. B.; KAY, D.; ENANORIA, W.; HALLER, L.; COLFORD J. R. Water, sanitation, and hygiene interventions to reduce diarrhoea in less developed countries: a 
systematic review and meta-analysis. Lancet InfectDis, 5: 42-52, 2005.

https://doi.org/10.1016/S1473-3099(04)01253-8

G1.COM. Governo do ES e MG se unem para reconstruir cidades afetadas por lama. 2015.

Disponível em: <http://g1.globo.com/espirito-santo/desastre-ambiental-no-rio-

doce/noticia/2015/12/governos-do-es-e-mg-se-unem-para-reconstruir-cidades-afetadas-por-

lama.html>. Acesso em: 16 nov. 2017.

IBAMA - Instituto Brasileiro do Meio Ambiente e dos Recursos Naturais Renováveis. Laudo Técnico Preliminar. Impactos ambientais decorrentes do desastre envolvendo o rompimento da barragem de Fundão, em Mariana, Minas Gerais. Brasília: 2015. Disponível em:<http://www.ibama.gov.br/phocadownload/barragemdefundao/laudos/laudo_tecnico_preliminar_lb ama.pdf >. Acesso em: out. de 2017.

IDE- SISEMA- Infraestrutura de Dados Espaciais do Sistema Estadual de Meio Ambiente e Recursos Hídricos. Bases Cartográficas Digitais. 2017. Disponível em: <

http://idesisema.meioambiente.mg.gov.br/>. Acesso em: Maio de 2017.

IGAM - Instituto Mineiro de Gestão das Águas. Bases Cartográficas Digitais. 2017.Disponível em: < http://www.igam.mg.gov.br/index.php?option=com_content\&task=view\&id=90\&ltemid=147> Acesso em: Maio de 2017.

IMADA, K. S.; ARAÚJO, T. S.; MUNIZ, P. T.; PÁDUA, V. L. Fatores socioeconômicos, higiênicos e de saneamento na redução de diarreia na Amazônia.Rev Saúde Pública, v.55, n.70, p. 1-11, 2016.

Instituto Brasileiro de Geografia e Estatística - IBGE. Catálogo de Downloads de Geociências. 2016. Disponível em: < https://downloads.ibge.gov.br/downloads_geociencias.htm>. Acesso em: maio de 2017.

JOVENTINO, E. S.; FREITAS, L. V.; VIEIRA, N. F. C.; AQUINO, P. S.; PINHEIRO, A. K. B.; XIMENES, L. B. Habilidades maternas para prevenção e manejo da diarreia infantil.Ciência y enfermeria. v. XIX, n. 2, p. 67-76, 2013. https://doi.org/10.4067/S0717-95532013000200007

PEREIRA, I. V.; CABRAL, I. E. Diarréia Aguda em crianças menores de um ano: subsídios para o delineamento do cuidar. Esc Anna Nery RevEnferm. v.12, n.2, p. 224-229, 2008. https://doi.org/10.1590/S1414-81452008000200004

PORTELA, R. A.; SOUTO, V. M. S.; LEITE, V. D.; TORQUATO, S. C. A incidência de doenças diarreicas e a sua relação com a ausência de saneamento: uma revisão bibliográfica.Hygeia Revista Brasileira de Geografia Médica e da Saúde, v.7, n.13, p.150-156, 2011.

QUEIROZ, J. T. M.; ROSENBERG, M. W.; HELLER L.; ZHOURI, A. L. M.; SILVA, S. R. News about Tap and Bottled Water: Can This Influence Peoples's Choices? Journal of Environmental Protection, v.3, n.4, p. 324-333, 2012. https://doi.org/10.4236/jep.2012.34041

$R$ Core Team (2018). R: A language and environment for statistical computing. $R$ Foundation for Statistical Computing, Vienna, Austria. URL https://www.R-project.org/.

RAZZOLINI, M. T. P.; GUNTHER, W. M. R. Impactos das Deficiências de Acesso a Água.Saúde e Sociedade, v.17, n.1, p.21-32, 2008. https://doi.org/10.1590/S0104-12902008000100003

REIS, P. R. C.; SILVEIRA, S. F. R.; COSTA, I. S. Caracterização Socioeconômica da Bacia do Rio Doce: Identificação de Grupos Estratégicos por meio de Análise Multivariada.In: II Encontro Mineiro de Administração Pública, Economia Solidária e Gestão Social. Viçosa: 2010.

ROCHA, M. A. G. Associação espacial entre mortalidade infantil e precipitação pluviométrica no Estado de Pernambuco. São Paulo, 2012. Tese (Doutorado) - Faculdade de Saúde Pública, Universidade de São Paulo, 2012.

ROCHA, E. M.; MORAES, L. G. M.; ALMEIDA, L. V.; DALVI, L. R.; ANDRIATO, L. C.; BERGAMASCHI, L. K.; BERNADINA, L. S. D.; PEREIRA, W. B.; GIMENEZ, V. G.; NETO, O. C.; ALMEIDA, H. S. Impacto do rompimento da barragem em Mariana-MG na saúde da população ribeirinha da cidade de Colatina-ES. Tempus, actas de saúde colet, v.10, n.3, p. 31-45, 2016. https://doi.org/10.18569/tempus.v10i3.1902

RUBINGER, S. D. Desvendando o conceito de saneamento no Brasil: uma análise da percepção da população e do discurso técnico contemporâneo. Belo Horizonte, 2008. Dissertação 
(mestrado) - Pós-Graduação em Saneamento, Meio Ambiente e Recursos Hídricos da Faculdade de Engenharia da Universidade Federal de Minas Gerais, 2008.

SABINO, L. M. M. Cartilha educativa para promoção da autoeficácia materna na prevenção da diarreia infantil: elaboração e validação. Fortaleza, 2016. Dissertação (mestrado) - Faculdade de Farmácia, Odontologia e Enfermagem, Universidade Federal do Ceará, 2016.

SNIS - Sistema Nacional de Informações em Saneamento do Ministério das Cidades. Série Histórica. 2017. Disponível em: < http://app4.cidades.gov.br/serieHistorica/>. Acesso em: Junho de 2017.

SOUZA, C. M. N.; FREITAS, C. M. O Saneamento na Ótica de Profissionais de Saneamento-SaúdeAmbiente: promoção da saúde ou prevenção de doenças?Eng. sanit. ambient. v. 13, n. 1, p. 46-53, 2008. https://doi.org/10.1590/S1413-41522008000100007

SOUSA, M. N. A.; QUEMELO, P. R. V. Q. Saúde do trabalhador e riscos ocupacionais na mineração.Rev. Bras. Pesq. Saúde, v.17, n.2, p. 111-121, 2015.

https://doi.org/10.21722/rbps.v17i2.13195

TEIXEIRA, J. C.; PUNGIRUM, M. E. M. C. Análise da associação entre saneamento e saúde nos países da América Latina e do Caribe, empregando dados secundários do banco de dados da Organização Pan-Americana de Saúde - OPAS.Rev. bras. epidemiol, v.8, n.4, p. 365-376, 2005. https://doi.org/10.1590/S1415-790X2005000400005

UOL.COM. Ministério Público pede suspensão da captação de água no Rio Doce. 2015.

Disponível em: <https://tvuol.uol.com.br/video/ministerio-publico-pede-suspensao-da-captacao-deagua-do-rio-doce-04024C1A366AE4B15326>. Acesso em: nov. de 2017.

UNICEF -United Nations Children's Fund. The state of the world's children 2014 in numbers: every child counts. Revealing disparities, advancing children's rights. UNICEF, New York, 2014, $116 \mathrm{p}$. 